\title{
Chitosan Biopolymers for Analysis of Organic Acids in Aquatic Environments of Treatment Wetlands
}

\author{
Mohamed H. Mohamed1', Kerry M. Peru², John V. Headley², Lee D. Wilson ${ }^{*}$ \\ ${ }^{1}$ Department of Chemistry, University of Saskatchewan, Saskatoon, Canada \\ ${ }^{2}$ Water Science and Technology Directorate, Environment and Climate Change Canada, Saskatoon, Canada \\ Email: *lee.wilson@usask.ca
}

How to cite this paper: Mohamed, M.H., Peru, K.M., Headley, J.V. and Wilson, L.D. (2017) Chitosan Biopolymers for Analysis of Organic Acids in Aquatic Environments of Treatment Wetlands. Journal of Geoscience and Environment Protection, 5, 214-225.

https://doi.org/10.4236/gep.2017.56019

Received: July 5, 2017

Accepted: July 18, 2017

Published: July 21, 2017

\begin{abstract}
Herein, we report on the use of chitosan-based engineered materials for the sequestration of naphthenic acid fraction compounds (NAFCs) and other species (matrix) in oil sands process-affected water (OSPW) in order to improve monitoring of NAFCs after phytoremediation. Chitosan pellets (CPs) were cross linked with glutaraldehyde (GLU) at variable feed ratios and characterized using thermogravimetric analysis (TGA). Sorption studies at equilibrium and kinetic conditions were carried on OSPW extract, raw and treated wetland samples. The materials were shown to have similar sorption capacity for NAFCs but with variable selectivity of the species in the complex mixture. As well, the matrix uptake varied according to the type of OSPW. Overall, CP in its native form outperformed the cross linked CP pellets, as evidenced by a reduction in matrix effects.
\end{abstract}

\section{Keywords}

Chitosan, Adsorbent, Organic Acid Contaminants, Sorption, Matrix Effects

\section{Introduction}

One of the great environmental water pollutants in Canada is oil sands process-affected water (OSPW) from the province of Alberta [1]. OSPW cannot be discharged back to the environment due toxicity and concerns about its complex chemical composition, as reflected by the zero-discharge policy by the Alberta Environmental Protection and Enhancement Act (1993). This had led to the accumulation of over 1 billion cubic meters of OSPW at oil mining sites in storage ponds of northern Alberta.

The origins of the main toxicity of OSPW have been attributed to naphthenic 
acids (NAs) which are the acid-extractable fraction of OSPW [2]. Researchers engaged in NAs-related research have contemplated the usage of alternative terms such as "acid extractable organics" (AEOs), "oil sands tailings water acid-ex- tractable organics" (OSTWAEO), or "naphthenic acid fraction compounds" (NAFCs) [3]. In this work, we use the latter term.

Various methods have been proposed for the remediation of OSPW [4]. One of them includes the use of wetland plants to metabolize NAFCs to form by-products that are less toxic [5] [6]. However, the limitation of this method is in the quantification of NAFCs after the wetland treatment where fatty acids and humic-like materials that are produced may yield false positive NAFC concentration levels, based on conventional extraction methods such as liquid- liquid extraction. As well, such conventional methods have shown to favour isolated chemical species with higher carbon chains and molecular weight [6] [7]. Background effects (salinity, suspended and dissolved solids, etc.) are also known to influence the formation of ions when using electrospray mass spectrometry as an analytical tool for measuring the variation in concentration of NAFCs [8].

This research work addresses a primary objective to develop a solid-phase extraction method using biopolymers [9] [10] which can subsequently be applied for Orbitrap MS characterization concerning the fate and distribution of NAFCs and process chemicals within treatment wetlands. The biopolymers can help address the problems related to limitations on detection limits and variability of results by selective extraction and/or reduction of matrix effects in OSPW. The improvements in solid-phase extraction (SPE) are anticipated to occur via preconcentration of naphthenic acids and minimization of other background interferents. We anticipate the use of such sorbent materials will contribute to further efforts in remediation of waterborne contaminants such as phytoremediation technology [5] [6].

\section{Experimental Section}

\subsection{Materials}

Chitosan (C) was obtained from Marinard Biotech (QC, Canada). $50 \mathrm{wt} \%$ glutaraldehyde solution $(\mathrm{G})$, acetonitrile, ammonium hydroxide, potassium bromide $(\mathrm{KBr})$ were obtained from Sigma-Aldrich (ON, Canada). 2 dram vials (screw thread with polyvinyl-faced pulp lined closure), hydrochloric acid and glacial acetic acid were obtained from Fisher Scientific (ON, Canada). OSPW (extract, raw water and treatment wetland) was obtained from the Water Science and Technology Directorate (Saskatoon, SK.) lab. $2 \mathrm{~mL}$ HPLC amber vials with screw-cap perforated Teflon-lined septa from Canadian Life Science (AB, Canada). All the materials used for the synthesis were used as received without further purification. Hereafter, we will refer to the three types of OSPW as extract, raw and wetland.

\subsection{Polymer Preparation}

Four biopolymers ( $c f$. Figure 1) were synthesized from pelletized chitosan (CP) 
via cross-linking with glutaraldehyde (varied by the level of glutaraldehyde; chitosan monomer: glutaraldehyde) i.e. 1:0.25 (CGP-1), 1:0.5 (CGP-2), 1:1 (CGP-3) and 1:2 (CGP-4) The synthesis was adapted from previous work with slight modification [11].

\subsection{Characterization and Leaching Test}

Thermal weight loss profiles of the materials were obtained using a TA Instruments Q50 TGA system at a heating rate of $5^{\circ} \mathrm{C} \cdot \mathrm{min}^{-1}$ to a maximum temperature of $900^{\circ} \mathrm{C}$ using nitrogen as the carrier gas. The thermal stability of the respective polymer components are reported as first derivative plots of weight/ temperature $\left(\% /{ }^{\circ} \mathrm{C}\right)$ against temperature $\left({ }^{\circ} \mathrm{C}\right)$.

The cross linked chitosan pellets were soaked in Millipore water for $24 \mathrm{~h}$ and analyzed using a double beam spectrophotometer (Varian CARY 100) at $295 \pm$ $0.5 \mathrm{~K}$.

\subsection{Sorption}

Approximately $75 \mathrm{ppm}$ of an OSPW extract was prepared from stock of greater concentration ( $2800 \mathrm{ppm}, \mathrm{pH} 10.5)$. CP and CGP-X (X denotes glutaraldehyde content) materials were imbibed in $5 \mathrm{~mL}$ of the OSPW raw solution for $48 \mathrm{~h}$ ( $c f$.

Figure 2). The solution uptake after sorption was analyzed using electrospray ionization high resolution mass spectrometry (ESI-HRMS) in negative-ion mode according to a method reported previously [12]. In the case of the treatment Wetland ( $\mathrm{pH}$ 8.61) and OSPW raw ( $\mathrm{pH}$ 9.18) samples, the sorption isotherms were obtained by equilibration of $10 \mathrm{~mL}$ of the water samples with the $\mathrm{CP}$ and CGP-X materials for $48 \mathrm{~h}$ of equilibration. Solid phase extraction (SPE) [12] was conducted on the wetland samples prior to analysis by ESI-HRMS.

Metal analyses of the OSPW samples were analyzed using an Agilent 7900 inductively coupled plasma-optical emission spectrometry photo (ICP-MS). The procedure followed SOP number: Chm-522-Standard Methods for the Examination of Water and Wastewater, Part 3125, APHA-AWWA-WEF without modification.

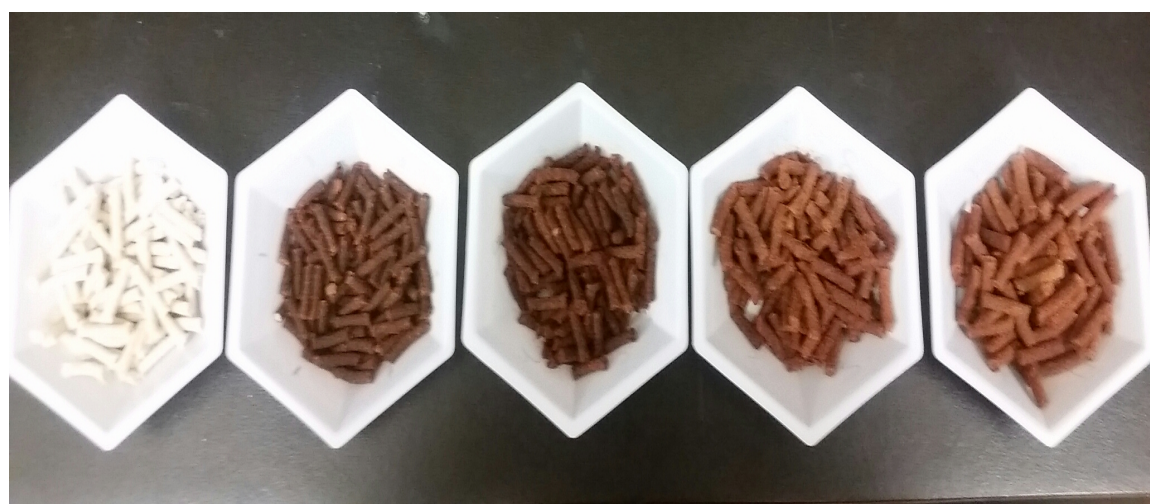

Figure 1. Chitosan biopolymers prepared herein from left to right: CP, CGP-1, CGP-2, CGP-3 and CGP-4, respectively. 


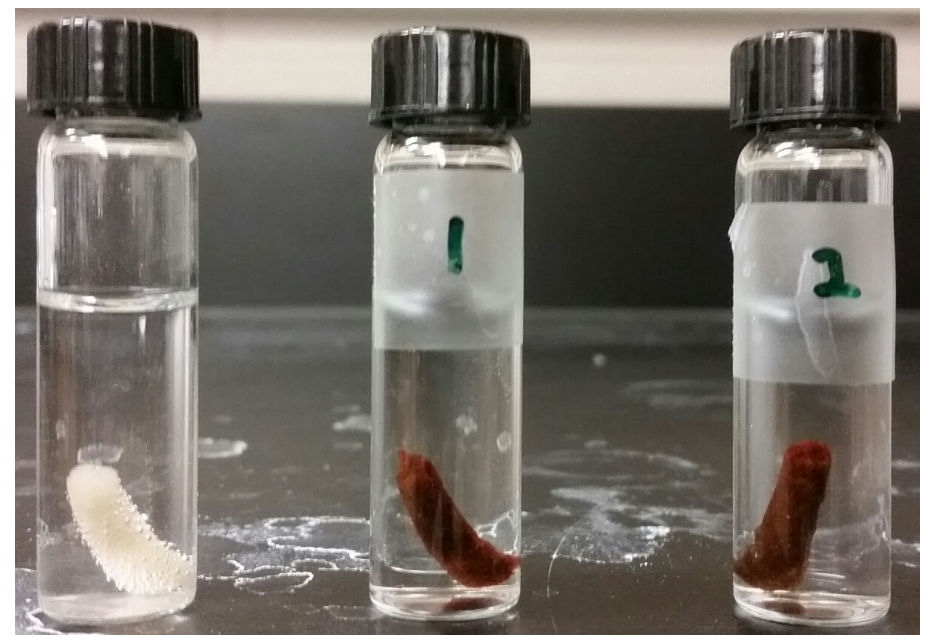

Figure 2. Imbibing of pelletized samples in the OSPW extract for the solid phase extraction setup with CP, CGP-1 and CGP-2, from left to right, respectively.

\section{Results and Discussion}

\subsection{Characterization and Leaching Test}

In a previous study, characterization of similar cross-linked polymers in powdered form was described in detail [11]. In this study, TGA was used to characterize the chitosan material in pelletized form (without crushing into powder). Figure 3 illustrates the thermal decomposition profile each respective material. A thermal event occurs between $400^{\circ} \mathrm{C}-500^{\circ} \mathrm{C}$ and relates to cleavage of the cross-linker where an increase in its peak area strongly correlates to incremental cross-linker content according to the synthetic preparation [11].

Figure 4 illustrates the leaching results of glutaraldehyde from various CGP-X materials after equilibration in water for $24 \mathrm{~h}$. CGP-3 and CGP-4 have absorption bands observed between 250 - $350 \mathrm{~nm}$ (range for glutaraldehyde) despite extensive washing in triplicate with Millipore water. This indicates that the cross-linker was not fully reacted with chitosan or undergoes hydrolysis at the variable levels of cross-linking. For the purpose of this study, several pelletized samples were studied with the wetland and OSPW extract, as follows: CP, CGP-1 and CGP-2.

\subsection{Sorption Studies}

\subsubsection{Equilibrium Studies}

Table 1 shows the monolayer sorption capacity ( $Q_{e} ; \mathrm{mg} / \mathrm{g}$ ) [13] for various chitosan materials with naphthenic acid fraction components (NAFCs). Overall, sorption is higher for OSPW extract relative to treatment Wetland followed by OSPW raw. This could be due to less matrix effects from salts, dissolved organics, and suspended solids that influence the sorption sites of the CP materials. Overall, the pristine CP has better uptake of NAFCs despite the fact that the material is not cross-linked with glutaraldehyde and suggests that the amine group of chitosan plays a key role in the adsorption of OSPW components. The matrix in this case could be salts, organics, and other UV-active compounds in 


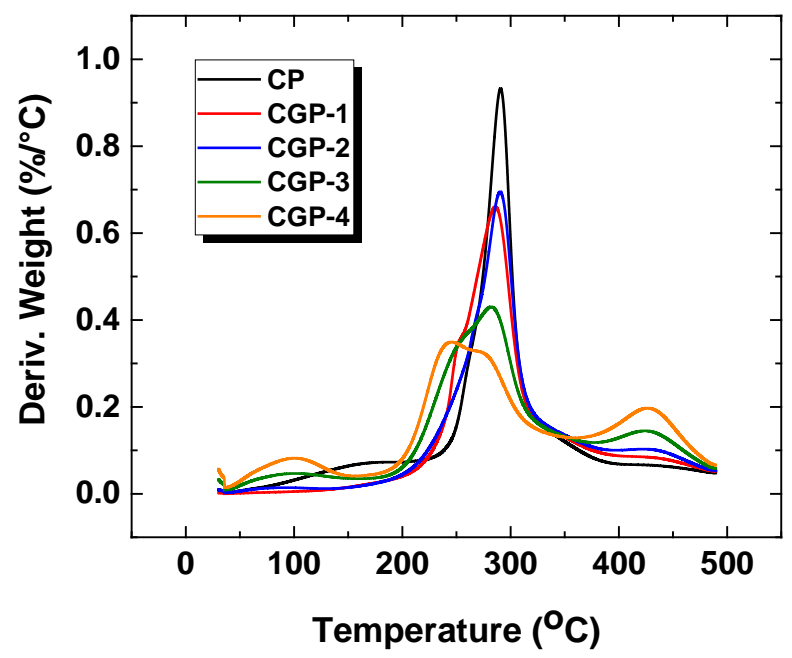

Figure 3. TGA results of a pristine chitosan pellet (no cross-linking) and pellets with variable cross-linking (CGP-X; where $\mathrm{X}=1,2,3$ and 4 ).

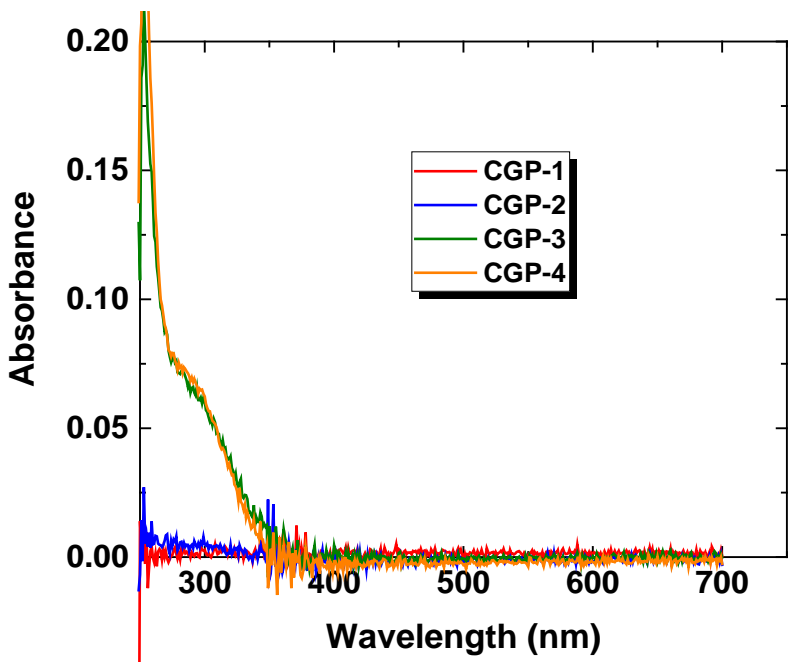

Figure 4. Absorbance of Millipore water washings after equilibrating CGP-X materials for $24 \mathrm{~h}$ at ambient conditions.

Table 1. Sorption capacities ( $\left.Q_{e} ; \mathrm{mg} / \mathrm{g}\right)$ for OSPW Wetland, raw and extract samples using $\mathrm{CP}$ and CGP-X biomaterials.

\begin{tabular}{cccc}
\hline & $\begin{array}{c}\text { Wetland } \\
\left(\mathrm{Q}_{\mathrm{e}}, \mathrm{mg} / \mathrm{g}\right)\end{array}$ & $\begin{array}{c}\text { Raw } \\
\left(\mathrm{Q}_{\mathrm{e}}, \mathrm{mg} / \mathrm{g}\right)\end{array}$ & $\begin{array}{c}\text { Extract } \\
\left(\mathrm{Q}_{\mathrm{e}}, \mathrm{mg} / \mathrm{g}\right)\end{array}$ \\
\hline $\mathrm{CP}$ & 18.5 & 1.65 & 26.2 \\
$\mathrm{CGP}-1$ & 4.41 & 0.188 & 27.6 \\
$\mathrm{CGP}-2$ & 9.54 & 1.18 & 27.2 \\
\hline
\end{tabular}

the samples.

To analyze the potential role of mineral matrix effects such as calcium, magnesium and sodium were measured using ICP-OES before and after incubation with the pellet materials ( $c$. Table 2). The materials were unaffected in the OSPW raw sample; however, in the case of the Wetland sample, the CP material 
sequestered $40 \%$ of the calcium and $20 \%$ of sodium; whereas, negligible uptake of magnesium was observed. Interestingly, the treated Wetland sample had relatively low sodium content (monovalent salt) while more calcium and magnesium divalent ions were noted relative to the composition of the OSPW raw sample. As well, the UV-active species were analyzed using the CARY 100 ( $c f$. Figure 5(a) and Figure 5(b). Figure 5(a) illustrates the UV spectra of the stock solutions for Wetland, OSPW raw and extract. As shown, OSPW raw has more UV-active species more than the extract followed by the Wetland. The presence of such UV-active components may provide an explanation as to why the sorption capacity of the materials in OSPW raw (cf. Table 1) shows a differing efficiency. In the case of OSPW, a lower uptake capacity was noted that was related to the presence of more competing species (UV-active) which bind to the chitosan pellet materials. To confirm this, the OSPW raw sample was analyzed ( $c f$. Figure 5(b)) and the results confirm that the same is true for $\mathrm{CP}$ (attenuated absorbance) but not for the cross linked CP. As noted above, a key differentiation between $\mathrm{CP}$ and cross-linked $\mathrm{CP}(\mathrm{CP}-\mathrm{X})$ relates to the presence of greater numbers of amine groups in the chitosan framework which may serve as favourable binding sites for selected chemical species [14] [15].

\subsubsection{Speciation Profiles}

Figures $6(\mathrm{a})-(\mathrm{c})$ illustrate the speciation profiles of Wetland, OSPW and
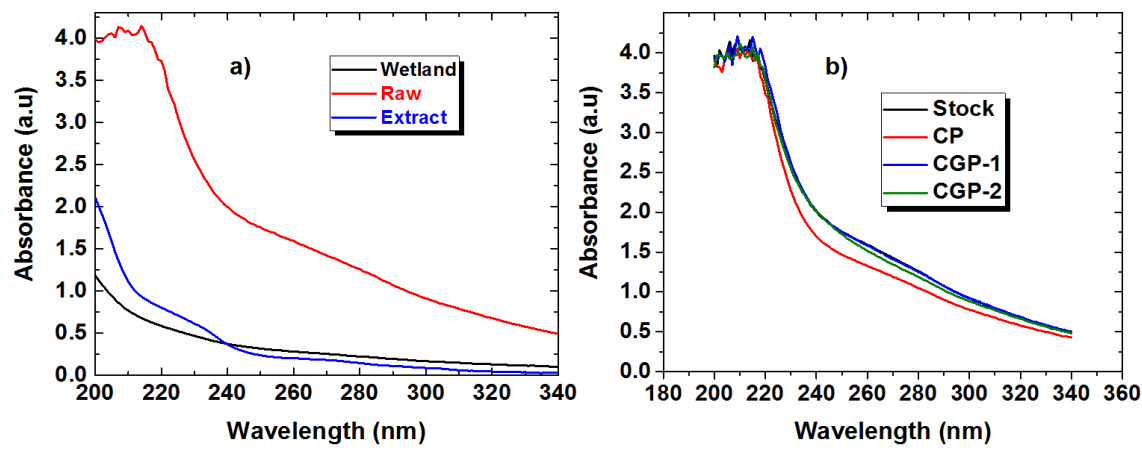

Figure 5. UV Spectra result; a) Stock for Wetland, OSPW raw and extract before adsorption and b) Wetland stock and after adsorption with CP and CP-X materials.

Table 2. Metal ion composition of calcium, magnesium and sodium species before and after incubation of the OSPW raw and Wetland with CP and CGP-X biomaterials at ambient conditions.

\begin{tabular}{ccccccc}
\hline Raw & \multicolumn{3}{c}{ Wetland } \\
\hline $\begin{array}{c}\text { Calcium } \\
(\mathrm{ppm})\end{array}$ & $\begin{array}{c}\text { Magnesium } \\
(\mathrm{ppm})\end{array}$ & $\begin{array}{c}\text { Sodium } \\
(\mathrm{ppm})\end{array}$ & $\begin{array}{c}\text { Calcium } \\
(\mathrm{ppm})\end{array}$ & $\begin{array}{c}\text { Magnesium } \\
(\mathrm{ppm})\end{array}$ & $\begin{array}{c}\text { Sodium } \\
(\mathrm{ppm})\end{array}$ \\
\hline Stock & 21 & 13 & 951 & 35 & 45 & 562 \\
CP & 20 & 13 & 935 & 21 & 48 & 447 \\
CGP-1 & 22 & 14 & 947 & $\mathrm{NA}^{*}$ & $\mathrm{NA}^{*}$ & $\mathrm{NA}^{*}$ \\
CGP-2 & 25 & 16 & 970 & $\mathrm{NA}^{*}$ & $\mathrm{NA}^{*}$ & $\mathrm{NA}^{*}$ \\
\hline
\end{tabular}

$\mathrm{NA}^{*}$; Not analyzed due to insufficient samples. 
OSPW extracts, respectively. The profiles differ significantly and in the case of Wetland sample ( $c$. Figure 6(a)), the profile reveals various congener species of NAFCs that exceed 1 ppm levels: $\mathrm{NO}_{3}, \mathrm{O}_{2}, \mathrm{O}_{2} \mathrm{~S}, \mathrm{O}_{3}, \mathrm{O}_{4}, \mathrm{O}_{5}, \mathrm{O}_{5} \mathrm{~S}, \mathrm{O}_{6}$ and $\mathrm{O}_{7}$. The main species for Wetland is $\mathrm{O}_{4}$ followed by $\mathrm{O}_{3}, \mathrm{O}_{5}, \mathrm{O}_{6}$ and $\mathrm{O}_{2}$, respectively. This is expected from process-treated samples by either UV or microwave conditions. [16] A similar profile is observed for OSPW (cf. Figure 6(b)) where $\mathrm{O}_{4}$ species are often higher in composition, followed by $\mathrm{O}_{3}$ species. However, $\mathrm{O}_{2}$ is present at higher abundance over $\mathrm{O}_{5}$ and $\mathrm{O}_{6}$ species, respectively. This also indicates degradation of OSPW has commenced due to the presence of the oxidized

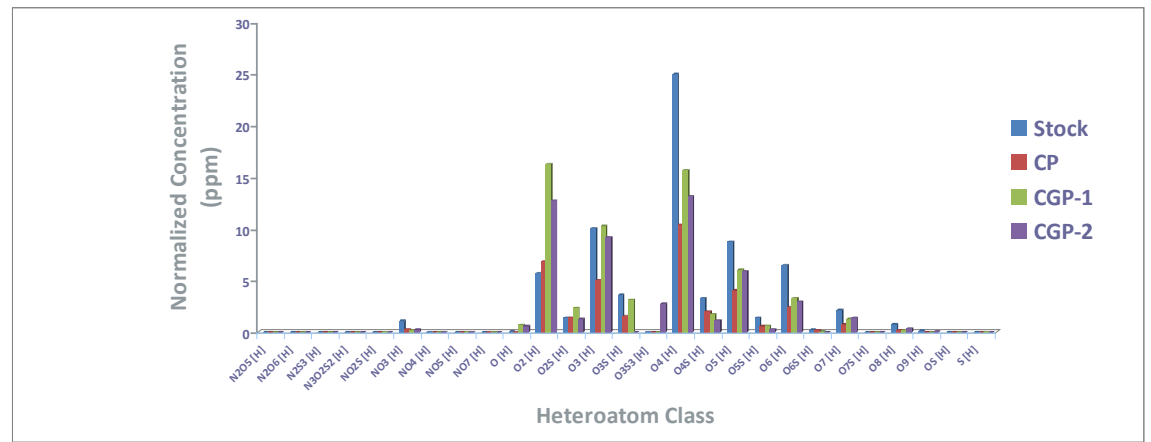

(a)

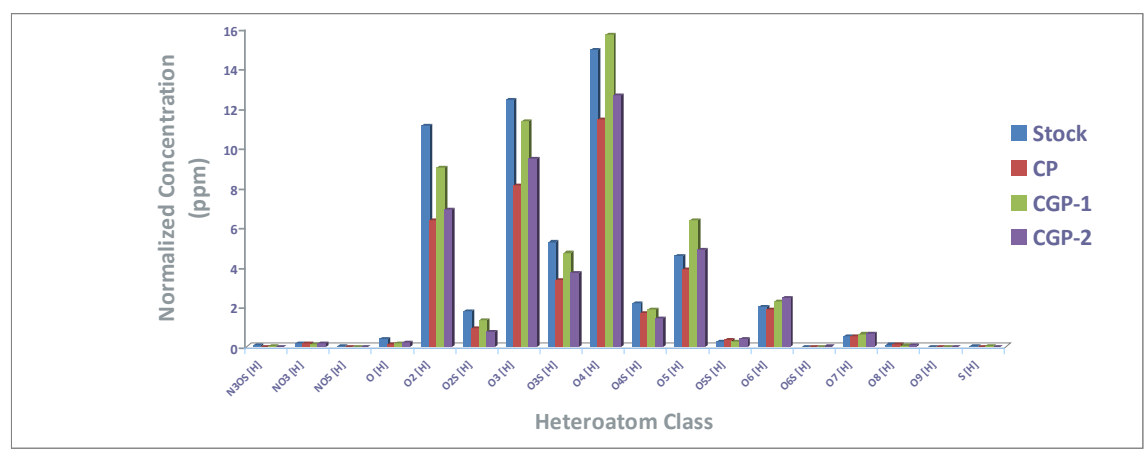

(b)

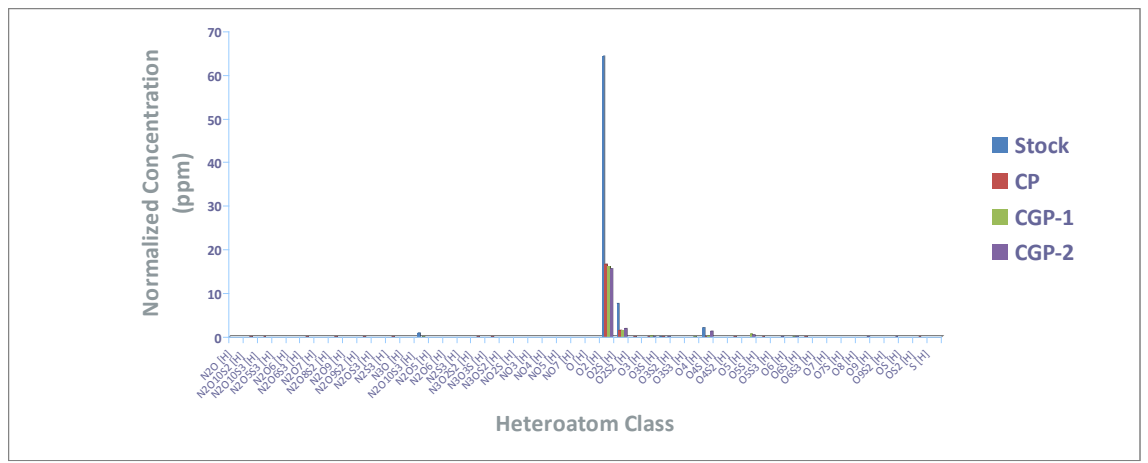

(c)

Figure 6. (a) ESI-HRMS speciation profiles of Wetland after sequestration with $\mathrm{CP}$, CGP-1 and CGP-2 at ambient conditions; (b) ESI-HRMS speciation profiles of OSPW Raw after sequestration with CP, CGP-1 and CGP-2 at ambient conditions; (c) ESIHRMS speciation profiles of OSPW Extract after sequestration with CP, CGP-1 and CGP-2 at ambient conditions. 
forms, perhaps due to microbial oxidation. The OSPW extract profile (cf. Figure 6(c)) reveals the following species with concentrations above $1 \mathrm{ppm}, \mathrm{O}_{2}, \mathrm{O}_{2} \mathrm{~S}$ and $\mathrm{O}_{4}$ species. Unlike the Wetland and OSPW samples, the main species for the OSPW extract is $\mathrm{O}_{2}$ followed by $\mathrm{O}_{3}$ and $\mathrm{O}_{4}$, respectively.

\subsubsection{Selective Removal of Species}

The percentage uptake removal for the species is shown in Figures 7(a)-(c) for

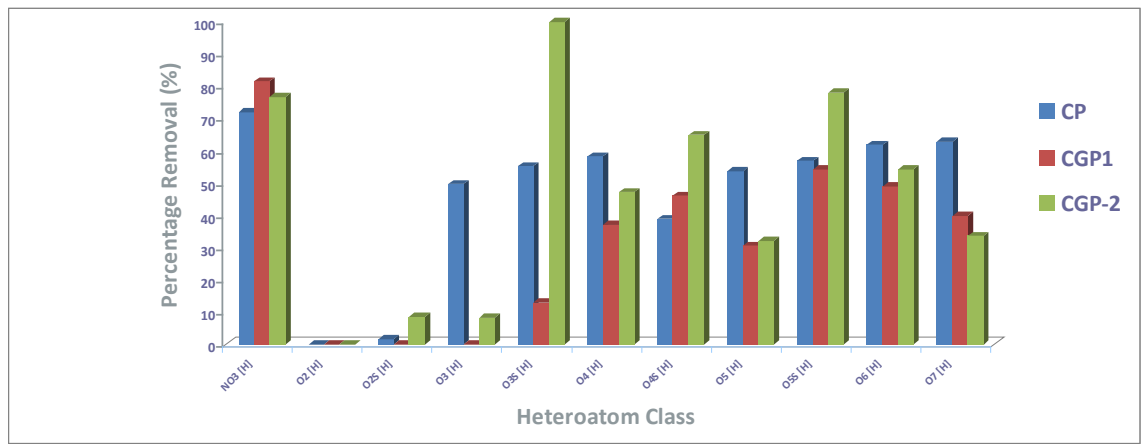

(a)

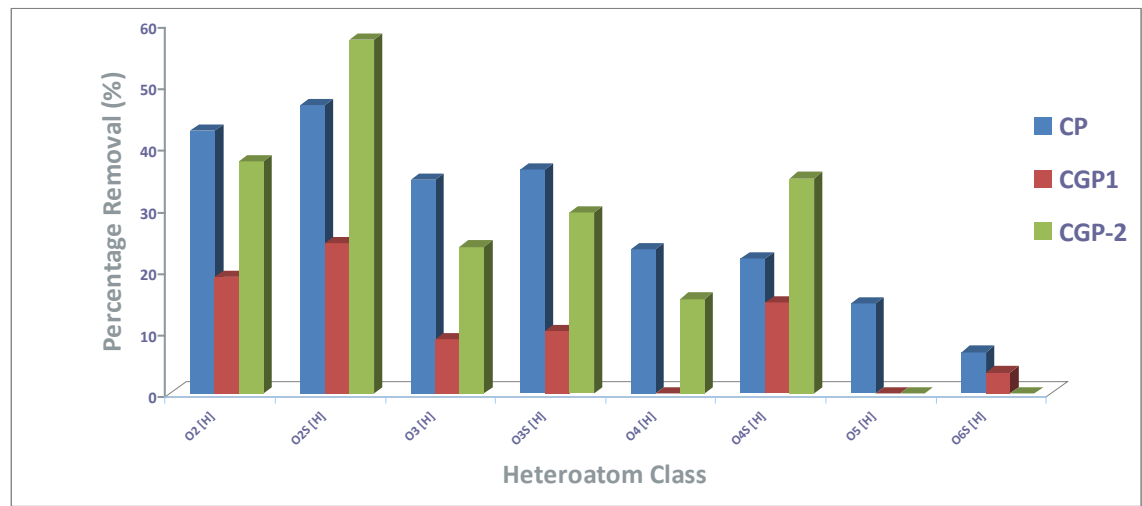

(b)

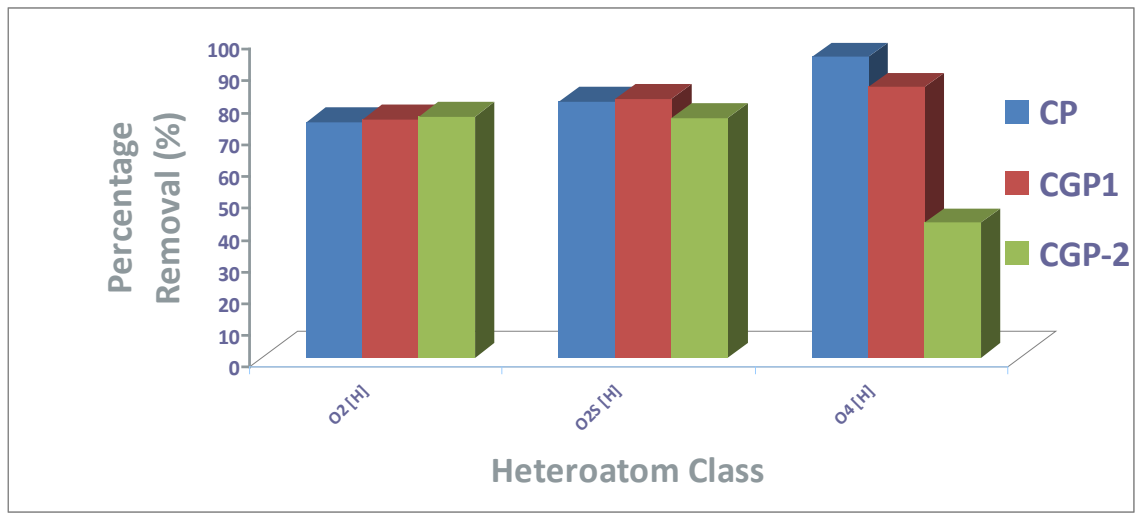

(c)

Figure 7. (a) Percentage removal species in the Wetland sample after sequestration with CP, CGP-1 and CGP-2 at ambient conditions; (b) Percentage removal species in the OSPW Raw sample after sequestration with CP, CGP-1 and CGP-2 at ambient conditions; (c) Percentage removal species in the OSPW Extract sample after sequestration with CP, CGP-1 and CGP-2. 
Wetland, OSPW and OSPW extract, respectively. In the case of Wetland and OSPW systems, there is evidence of selective removal of the NAFCs species. For instance, $\mathrm{CP}$ has more than 40\% removal (cf. Figure 7(a)) for all the species except $\mathrm{O}_{2}$ and $\mathrm{O}_{2} \mathrm{~S}$ while the same material has more than $40 \%$ removal for $\mathrm{O}_{2}$ and $\mathrm{O}_{2} \mathrm{~S}$ in OSPW and OSPW extract samples (cf. Figure 7(b) Figure 7(c)). The same is observed for CGP materials where they have no uptake for the $\mathrm{O}_{2}$ and $\mathrm{O}_{2} \mathrm{~S}$ species in the Wetland sample but do show measurable uptake in the OSPW and its extracts. This is attributed to matrix interference in the sorption process of the Wetland sample.

Although the CGP-2 material has overall less sequestration of NAFCs in Wetland sample, it has better removal of $\mathrm{O}_{3} \mathrm{~S}, \mathrm{O}_{4} \mathrm{~S}$ and $\mathrm{O}_{5} \mathrm{~S}$. In the case of the OSPW, $\mathrm{CP}$ reveals an overall attenuation of removal for species with more $\mathrm{O}$ content ( $c f$. Figure 7(b)) i.e. $\mathrm{O}_{2}$ and $\mathrm{O}_{2} \mathrm{~S}>\mathrm{O}_{3}$ and $\mathrm{O}_{3} \mathrm{~S}>\mathrm{O}_{4}$ and $\mathrm{O}_{4} \mathrm{~S}>\mathrm{O}_{5}$ and $\mathrm{O}_{5} \mathrm{~S}$. CGP materials did not follow similar trends for the same sample. The OSPW extract reveal different patterns where $\mathrm{CP}$ has a higher removal for the $\mathrm{O}_{4}$ species relative to $\mathrm{O}_{2}$ and $\mathrm{O}_{2} \mathrm{~S}$, while an opposite trend is true for CGP-2.

\subsubsection{Supporting Evidence of Binding Interactions}

Thermal analysis was used to provide supporting evidence of adsorbed OSPW and Wetland samples. Figure 8 shows the thermogram of CP after imbibing in Millipore water (MW; distilled and deionized), OSPW extract, raw and wetland samples, where the TGA samples represent analysis of the solid pellet after air-drying. A thermal event $\sim 170^{\circ} \mathrm{C}$ for both OSPW and its extract (absent in $\mathrm{MW}$ ) is attributed to decomposition of some of the species adsorbed by CP after imbibing in solution. In the case of Wetland, there is a broad small thermal event $\sim 170^{\circ} \mathrm{C}$ and a shoulder $\sim 230^{\circ} \mathrm{C}$ for the thermal event between $200^{\circ} \mathrm{C}$ $400^{\circ} \mathrm{C}$ that is absent in the CP-MW. Furthermore, the thermal events for chitosan decomposition $\left(200^{\circ} \mathrm{C}-400^{\circ} \mathrm{C}\right)$ vary for each sample. This further proves

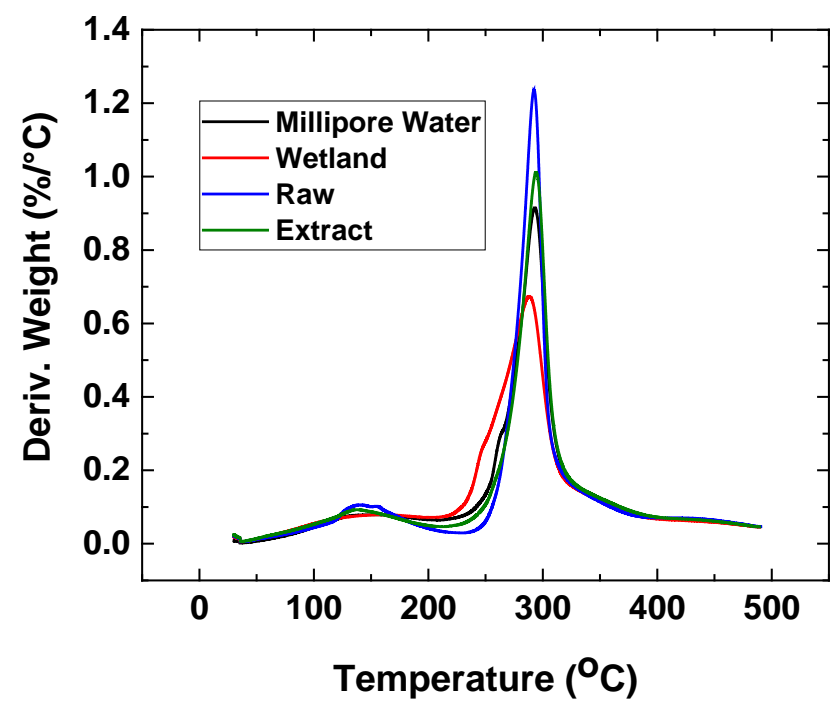

Figure 8. TGA of pristine chitosan pellet (CP) after soaking in Millipore water (MW), Wetland, OSPW and OSPW after solid phase extraction at ambient conditions. 
the variable interactions occur between chitosan with the sorbates (contaminants).

Physical differences were also observed after soaking CP in MW; OSPW extract and Wetland (cf. Figure 9). After soaking in MW, the CP pellet did not lose its shape after imbibing with subsequent air-drying. However, in the case of OSPW extract and Wetland, the shape differs from its original pellet morphology. The pellets are flexible but this effect is more pronounced after imbibing in the wetland sample. This relates to the salt effects in the matrix which influenced its swelling and adsorption properties.

\subsubsection{Kinetic Studies}

The kinetics of OSPW extract and wetland uptake with the CP biomaterial was studied using UV-analysis. CP was inserted in a quartz cell cuvette containing 3 $\mathrm{mL}$ of each respective sample and measured absorbance with time in-situ. Figure 10 illustrates the kinetics profile of $\mathrm{CP}$ with OSPW extract and wetland, where the latter fails to reach equilibrium after $24 \mathrm{~h}$, while the former material achieves dynamic equilibrium for these conditions. Moreover, OSPW extract reveal that multi-step uptake occurs while the wetland sample is adsorbed continuously until the system reaches dynamic equilibrium.

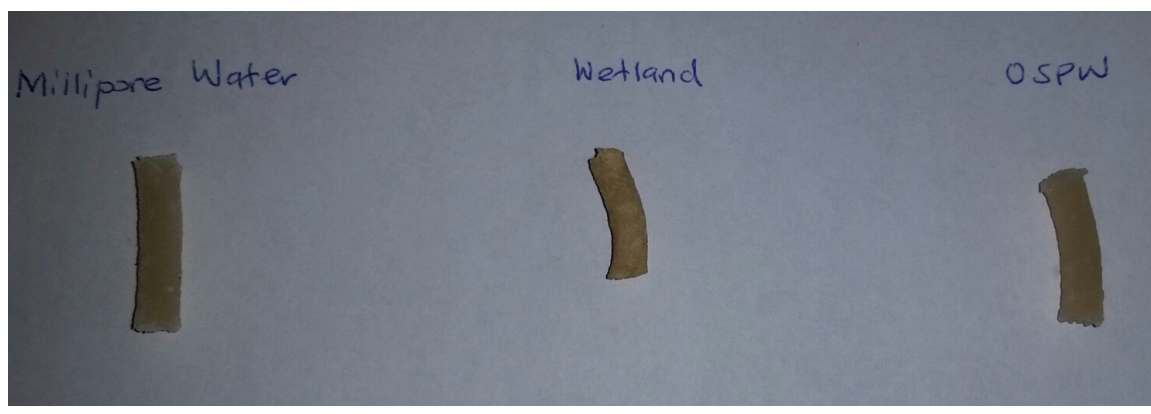

Figure 9. Image of the $\mathrm{CP}$ biomaterial after sorption with Millipore water, wetland and OSPW raw after solid phase extraction at ambient conditions.

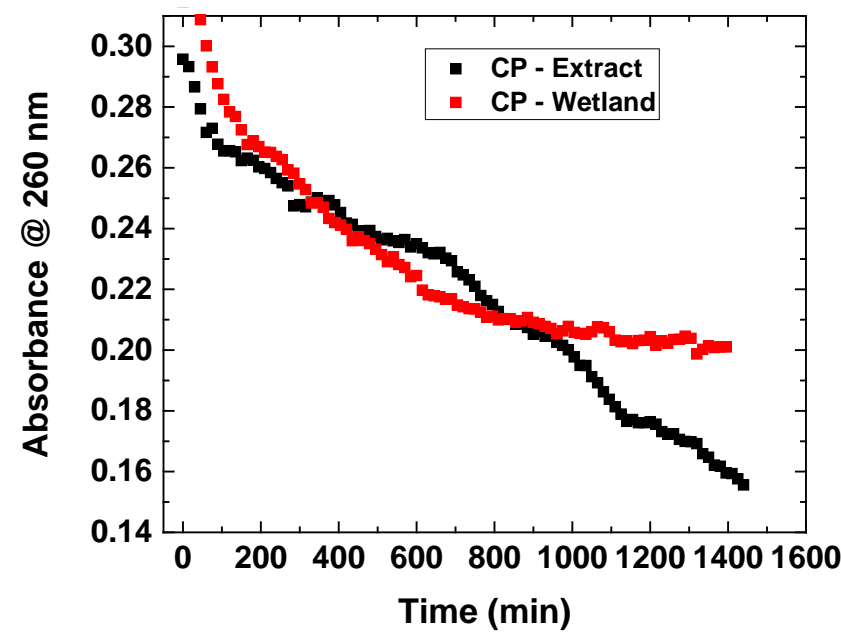

Figure 10. Absorbance of OSPW extract and wetland measured at $260 \mathrm{~nm}$ with time at ambient conditions. 


\section{Conclusions}

This study was aimed at evaluation of the adsorption properties and utility of cross linked CP for the reduction of matrix effects and semi-quantification of NAFCs for the analyses of treatment wetland samples in phytoremediation. However, this study shows that $\mathrm{CP}$ materials without cross-linking are more suitable solid-phase extractants for sample cleanup and monitoring, as evidenced by the ability of such materials to sequester NAFCS, UV-active species, and various metal ions such as calcium and sodium in the treatment wetland samples.

\section{Acknowledgements}

The authors gratefully acknowledge Natural Resources Canada for supporting this project and the technical assistance of Mr. Jonathan Bailey with mass spectrometry analyses.

\section{Disclaimer}

As there is a lack of representative analytical standard methodologies for the analysis of total NAs or NAFCs, the results presented in this manuscript should be considered internally consistent, but may not be directly comparable to other results. For further information on the methods and analytical procedures used in this study, please contact the corresponding author.

\section{References}

[1] Mahaffey, A. and Dube, M. (2017) Review of the Composition and Toxicity of Oil Sands Process-Affected Water. Environmental Reviews, 25, 97-114.

https://doi.org/10.1139/er-2015-0060

[2] Allen, E.W. (2008) Process Water Treatment in Canada's Oil Sands Industry: I. Target Pollutants and Treatment Objectives. Journal of Environmental Engineering and Science, 7, 123-138. https://doi.org/10.1139/S07-038

[3] Headley, J.V., Peru, K.M. and Barrow, M.P. (2016) Advances in Mass Spectrometric Characterization of Naphthenic Acids Fraction Compounds in Oil Sands Environmental Samples and Crude Oil-A Review. Mass Spectrometry Reviews, 35, 311-328. https://doi.org/10.1002/mas.21472

[4] Quinlan, P.J. and Tam, K.C. (2015) Water Treatment Technologies for the Remediation of Naphthenic Acids in Oil Sands Process-Affected Water. Chemical Engineering Journal, 279, 696-714. https://doi.org/10.1016/j.cej.2015.05.062

[5] Armstrong, S.A., Headley, J.V., Peru, K.M. and Germida, J.J. (2009) Differences in Phytotoxicity and Dissipation between Ionized and Nonionized Oil Sands Naphthenic Acids in Wetland Plants. Environmental Toxicology and Chemistry, 28, 2167-2174. https://doi.org/10.1897/09-059.1

[6] Ajaero, C., McMartin, D.W., Peru, K.M., Bailey, J., Haakensen, M., Friesen, V., Martz, R., Hughes, S.A., Brown, C., Chen, H., McKenna, A.M., Corilo, Y.E. and Headley, J.V. (2017) Fourier Transform Ion Cyclotron Resonance Mass Spectrometry Characterization of Athabasca Oil Sand Process-Affected Waters Incubated in the Presence of Wetland Plants. Energy \& Fuels, 31, 1731-1740.

https://doi.org/10.1021/acs.energyfuels.6b02643 
[7] Brunswick, P., Shang, D., van Aggelen, G., Hindle, R., Hewitt, L.M., Frank, R.A., Haberl, M. and Kim, M. (2015) Trace Analysis of Total Naphthenic Acids in Aqueous Environmental Matrices by Liquid Chromatography/Mass SpectrometryQuadrupole Time of Flight Mass Spectrometry Direct Injection. Journal of Chromatography $A$, 1405, 49-71. https://doi.org/10.1016/j.chroma.2015.05.048

[8] Headley, J.V., Peru, K.M., Mohamed, M.H., Frank, R.A., Martin, J.W., Hazewinkel, R.R.O., Humphries, D., Gurprasad, N.P., Hewitt, L.M., Muir, D.C.G., Lindeman, D., Strub, R., Young, R.F., Grewer, D.M., Whittal, R.M., Fedorak, P.M., Birkholz, D.A., Hindle, R., Reisdorph, R., Wang, X., Kasperski, K.L., Hamilton, C., Woudneh, M., Wang, G., Loescher, B., Farwell, A., Dixon, D.G., Ross, M., Pereira, A.D.S., King, E., Barrow, M.P., Fahlman, B., Bailey, J., McMartin, D.W., Borchers, C.H., Ryan, C.H., Toor, N.S., Gillis, H.M., Zuin, L., Bickerton, G., McMaster, M., Sverko, E., Shang, D., Wilson, L.D. and Wrona, F.J. (2013) Chemical Fingerprinting of Naphthenic Acids and Oil Sands Process Waters-A Review of Analytical Methods for Environmental Samples. Journal of Environmental Science and Health, Part A, 48, 1145-1163. https://doi.org/10.1080/10934529.2013.776332

[9] Mohamed, M. and Wilson, L. (2015) Kinetic Uptake Studies of Powdered Materials in Solution. Nanomaterials, 5, 969-980. https://doi.org/10.3390/nano5020969

[10] Udoetok, I.A., Wilson, L.D. and Headley, J.V. (2016) Self-Assembled and CrossLinked Animal and Plant-Based Polysaccharides: Chitosan-Cellulose Composites and Their Anion Uptake Properties. ACS Applied Materials \& Interfaces, 8, 33197-33209. https://doi.org/10.1021/acsami.6b11504

[11] Mohamed, M.H., Udoetok, I.A., Wilson, L.D. and Headley, J.V. (2015) Fractionation of Carboxylate Anions from Aqueous Solution Using Chitosan Cross-Linked Sorbent Materials. RSC Advances, 5, 82065-82077.

https://doi.org/10.1039/C5RA13981C

[12] Mohamed, M.H., Wilson, L.D., Shah, J.R., Bailey, J., Peru, K.M. and Headley, J.V. (2015) A Novel Solid-State Fractionation of Naphthenic Acid Fraction Components From Oil Sands Process-Affected Water. Chemosphere, 136, 252-258. https://doi.org/10.1016/j.chemosphere.2015.05.029

[13] Mohamed, M.H., Wilson, L.D., Headley, J.V. and Peru, K.M. (2011) Sequestration of Naphthenic Acids from Aqueous Solution Using $\beta$-Cyclodextrin-Based Polyurethanes. Physical Chemistry Chemical Physics, 13, 1112-1122. https://doi.org/10.1039/C0CP00421A

[14] Mahaninia, M.H. and Wilson, L.D. (2016) Modular Cross-Linked Chitosan Beads with Calcium Doping for Enhanced Adsorptive Uptake of Organophosphate Anions. Industrial \& Engineering Chemistry Research, 55, 11706-11715. https://doi.org/10.1021/acs.iecr.6b02814

[15] Mahaninia, M.H. and Wilson, L.D. (2016) Cross-linked Chitosan Beads for Phosphate Removal from aqueous solution. Journal of Applied Polymer Science, 133, 42949. https://doi.org/10.1002/app.42949

[16] Headley, J.V., Peru, K.M., Mishra, S., Meda, V., Dalai, A.K., McMartin, D.W., Mapolelo, M.M., Rodgers, R.P. and Marshall, A.G. (2010) Characterization of Oil Sands Naphthenic Acids Treated with Ultraviolet and Microwave Radiation by Negative Ion Electrospray Fourier Transform Ion Cyclotron Resonance Mass Spectrometry. Rapid Communications in Mass Spectrometry, 24, 3121-3126. https://doi.org/10.1002/rcm.4754 
Submit or recommend next manuscript to SCIRP and we will provide best service for you:

Accepting pre-submission inquiries through Email, Facebook, LinkedIn, Twitter, etc. A wide selection of journals (inclusive of 9 subjects, more than 200 journals)

Providing 24-hour high-quality service

User-friendly online submission system

Fair and swift peer-review system

Efficient typesetting and proofreading procedure

Display of the result of downloads and visits, as well as the number of cited articles Maximum dissemination of your research work

Submit your manuscript at: http://papersubmission.scirp.org/

Or contact gep@scirp.org 